\title{
Eco-friendly Coating of Natural Zeolite with Metallic Gold, and Characterization of the Resulting Products
}

\author{
SALPRIMA YUDHA S $^{1 *}$, MORINA ADFA ${ }^{1}$ and ASWIN FALAHUDIN ${ }^{2}$ \\ 'Department of Chemistry, Faculty of Mathematics and Natural Sciences, \\ Universitas Bengkulu, Indonesia. \\ 2Jalan W.R, Supratman, Kandang Limun, Kota Bengkulu 38371A, Indonesia \\ ${ }^{*}$ Corresponding author E-mail: salprima@unib.ac.id \\ http://dx.doi.org/10.13005/ojc/340160
}

(Received: September 24, 2017; Accepted: December 05, 2017)

\begin{abstract}
A green method of coating natural zeolite with metallic gold, and characterizing the resulting products was developed. The product was obtained by dispersion of natural zeolite powder in $\mathrm{HAuCl}_{4}$ solution, followed by reduction of the $\mathrm{Au}^{3+}$ ions using Callophyllum inophyllum $\mathrm{L}$. leaves extract and subsequently calcined at $300{ }^{\circ} \mathrm{C}$. The characterization results show that element mapping using EDX did not definitively prove the presence of gold in the zeolite. However, the XRD results did suggest that metallic gold was present in the corresponding product.
\end{abstract}

Keywords: Callophyllum inophyllum L, Coating, Metallic gold, Natural zeolite.

\section{INTRODUCTION}

There are many reports on the modification of supporting materials to enhance the stability of gold nanoparticles, which have been developed for various purposes. For instance, calixarene-functionalized gold nanoparticles, which are potentially useful in colorimetric sensors involving $\mathrm{Cu}^{2+}$ and $\mathrm{Pb}^{2+}$ ions, have been prepared recently. ${ }^{1}$ However, zeolites also play an important role as supporting materials. For example, gold nanoparticles loaded onto zeolite can be used for laser mass spectrometry, ${ }^{2}$ and modified zeolitesupported gold nanoparticles are effective as an antibacterial agent or a peroxide sensor. ${ }^{3-4}$ Solidsupported gold nanoparticles are also useful as heterogenous or quasi-homogenous catalysts; zeolite-encapsulated gold nanoparticles are effective for the oxidation of bioethanol. ${ }^{5}$ and the in situ growth of Au nanoparticles (AuNPs) on $\mathrm{Fe}_{2} \mathrm{O}_{3}$ via a cysteine-linked approach, and their use as a catalyst for 4-nitrophenol reduction, has been reported recently. ${ }^{6}$ 
Moreover, there has been a rapid increase in the use of semiconductor materials such as $\mathrm{ZnO}$ and $\mathrm{TiO}_{2}$ as supporting materials. The authors of one report claim that the photocatalytic efficiencies of $\mathrm{Au} / \mathrm{TiO}_{2}$ and $\mathrm{Pt} / \mathrm{TiO}_{2}$ are higher than those of $\mathrm{Pd} /$ $\mathrm{TiO}_{2}$ with respect to the degradation of an aqueous solution of acid green $16 .{ }^{7}$ Recently, various organic dyes-including Methylene Blue, Methyl Orange, Congo Red, Rhodamine B (RhB), and Malachite Green-have been reductively degraded using an $\mathrm{Au} / \mathrm{CeO}_{2}-\mathrm{TiO}_{2}$ nanohybrid. ${ }^{8}$ Furthermore, the photocatalytic activity of an $\mathrm{Au} / \mathrm{TiO}_{2}$ nanocomposite, which can be used to remove RhB, has been enhanced by preparing it by chemical reduction using hydrazine hydrate. ${ }^{9}$ These findings have been corroborated by other research: a mesoporous $\mathrm{Au}-\mathrm{TiO}_{2}$ nanocomposite, prepared by a simple hydrolytic spray method, effectively decolorized aqueous $\mathrm{RhB}$ under visible light irradiation $(\lambda>420$ $\mathrm{nm}) .^{10}$ The catalytic degradation of RhB using $\mathrm{Au}$ loaded onto $\mathrm{TiO}_{2}$ nanotube arrays is enhanced by sunlight, ${ }^{11}$ and titania $\left(\mathrm{TiO}_{2}\right)$ - and zincite $(\mathrm{ZnO})$ supported gold nanoparticles have photodegradation activities with respect to RhB under UV-A light irradiation. ${ }^{12}$ Another example is the use of $\mathrm{TiO}_{2}$ doped with various metals. ${ }^{13}$ Other results show that multiwalled carbon nanotubes with heterooligophenylene-stabilized gold nanoparticles effectively degrade RhB in visible light. ${ }^{14}$ Recently, we have reported the environmentally friendly (green) synthesis of silver and gold nanoparticles using plant extracts; for example, we have synthesized gold nanoparticles using an extract from Calophyllum inophyllum L. leaves. Analysis revealed that spherical gold nanoparticles with an average diameter of $27 \mathrm{~nm}$ have a surface plasmon resonance peak at $539 \mathrm{~nm}^{15}$

The existing research has stimulated our interest in developing a green method of coating natural zeolite with metallic gold, and characterizing the resulting products. We believe our research will significantly contribute to the development of competitive green substances that are compatible with existing materials.

\section{EXPERIMENITAL}

\section{Material and Methods}

A natural zeolite was collected from Taba Penanjung, Bengkulu, Indonesia, and the $C$. Inophyllum $L$ leaves were taken from Bengkulu City, Indonesia. The gold ion precursor $\left(\mathrm{HAuCl}_{4} \cdot 3 \mathrm{H}_{2} \mathrm{O}\right)$ was purchased from Sigma-Aldrich (Germany). Demineralized water was used throughout.

\section{General procedure}

The natural zeolite was ground using a mortar until it was able to pass through a 200 mesh sieve $(75 \mu \mathrm{M})$. The fine particles were washed three times with demineralized water and dried at $100{ }^{\circ} \mathrm{C}$ for $2 \mathrm{~h}$ (we referred to the product as pre-treated natural zeolite). The pre-treated natural zeolite (10 g) was immersed in $50 \mathrm{~mL}$ of $30 \% \mathrm{H}_{2} \mathrm{O}_{2}$ and kept at room temperature for $40 \mathrm{~h}$ in the dark. The mixture was heated at $50^{\circ} \mathrm{C}$ for $1 \mathrm{~h}$ and $100^{\circ} \mathrm{C}$ for $1 \mathrm{~h}$, then centrifuged at $4500 \mathrm{rpm}$ for $5 \mathrm{~min}$. to obtain a solid. The solid material was washed with demineralized water and centrifuged up to three times at $4500 \mathrm{rpm}$ for $5 \mathrm{~min}$. (we referred to the product as $\mathrm{H}_{2} \mathrm{O}_{2}$-treated natural zeolite). The $\mathrm{H}_{2} \mathrm{O}_{2}$ treated natural zeolite $(1 \mathrm{~g})$ was then immersed in $0.01 \mathrm{M} \mathrm{HAuCl} 4$ solution for $24 \mathrm{~h}$. The C. Inophyllum L. Leaf extract was prepared by heating the airdried leaves $(2 \mathrm{~g})$ in hot demineralized water (100 $\mathrm{MI})$ for 30 minute. The fresh leaf extract $(25 \mathrm{MI})$ was added dropwise to the suspension of $\mathrm{HAuCl}$ /zeolite while stirring magnetically. The reaction mixture was aged at room temperature for $48 \mathrm{~h}$, then heated until the solvent had completely evaporated. The solid black material was then placed in a crucible and heated in a furnace at $300^{\circ} \mathrm{C}$ for $1 \mathrm{~h}$ to produce a solid dry material (Figure. 1).

\section{RESULTS AND DISCUSSION}

Figure. 1 is a flow diagram illustrating the process used to coat the natural zeolite with metallic gold. The overall color changed from solid gray (natural zeolite) to deep brown (gold-coated natural zeolite). $\mathrm{H}_{2} \mathrm{O}_{2}$ was used to remove organic compounds trapped in the natural zeolite. 


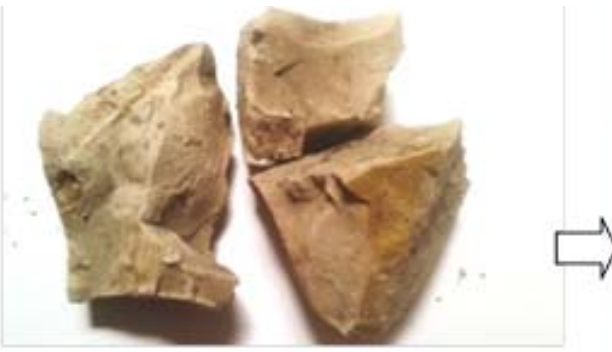

(a)

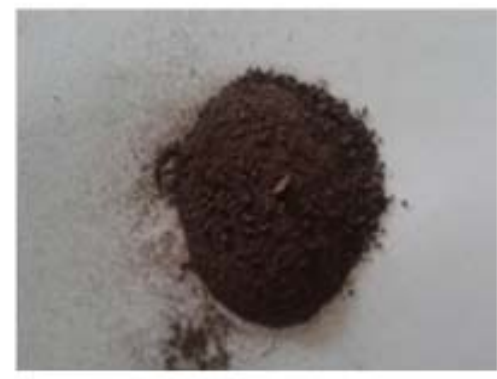

(d)

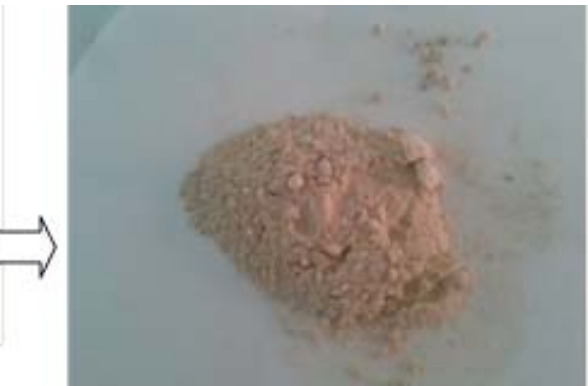

(b)

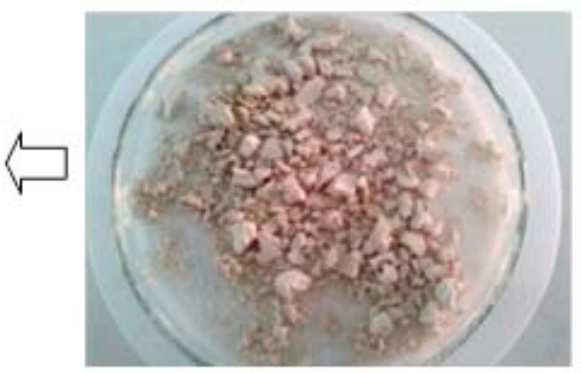

(c)

Fig.1.Treatment flow to from metallic gold-decorated natural zeolite;(a) raw natural zeolite,(b)natural zeolite powder 200 mesh, (c) $\mathrm{H}_{2} \mathrm{O}_{2}$-treated natural zeolite powder,(d)metallic gold-decorated natural zeolite

The immersion of the zeolite powder in $\mathrm{HAuCl}_{4}$ solution for $24 \mathrm{~h}$ ensured the impregnation of gold ions. The addition of $C$. inophyllum $\mathrm{L}$. leaf extract to the reaction mixture reduced the $\mathrm{Au}^{3+}$ to $\mathrm{Au}^{0}$, which was signaled by a change in the color of the reaction mixture from yellow to deep brown. The water was evaporated to produce a gel, which was calcined at $300^{\circ} \mathrm{C}$ for $1 \mathrm{~h}$ to remove the organic material residue from the solid material. We characterized the obtained materials $((1 b),(1 c)$, and (1d)) by X-ray diffraction (XRD), as shown in Figure. 2.

The pre-treated natural zeolite (Fig 2a) exhibited peaks at $2 \theta=20.06^{\circ}, 23.96^{\circ}, 26.86^{\circ}$, $35.32^{\circ}$, and $62.28^{\circ}$, and many other peaks indicating that the zeolite was in the amorphous phase. The peaks indicated that the clay comprised montmorillonite with its characteristic peaks at $2 \theta=$ $20.06^{\circ}, 35.32^{\circ}$, and $62.28^{\circ}$. The other peaks were attributable to impurities corresponding to feldspar $\left(23.96^{\circ}\right)$ and quartz $\left(26.86^{\circ}\right)$. These results are corroborated by those for other $\mathrm{Na}$-bentonite type zeolites ${ }^{16}$ However, the $\mathrm{H}_{2} \mathrm{O}_{2}$-treated natural zeolite (Fig 2b) exhibited peaks at $2 \theta=19.86^{\circ}, 26.64^{\circ}$, $36.96^{\circ}$, and $61.94^{\circ}$. The peak for feldspar $\left(23.96^{\circ}\right)$ disappeared during the treatment. The final material was also characterized by $\mathrm{XRD}$, and the results are shown in Fig 2c. The new peaks at $2 \theta=37.66^{\circ}$, $44.00^{\circ}, 64.22^{\circ}$, and $77.18^{\circ}$ were attributable to metallic gold, and are corroborated by similar results from other reports. ${ }^{17}$ Although there was no precise evidence showing the coating sites (on the surface or in the zeolite matrix), it was clear that the zeolite had been coated with metallic gold during the treatment.

We conducted further investigations using scanning electron microscopy (SEM) and energydispersive X-ray spectroscopy (EDX) to obtain more information about the morphology and elemental composition of the target materials, as shown in Figure. 3.

According to Fig. $3(\mathrm{a})$, the $\mathrm{H}_{2} \mathrm{O}_{2}$-treated natural zeolite comprised bulk particles with 
irregular shapes. Fig. 3 (b) shows the elements present in the $\mathrm{H}_{2} \mathrm{O}_{2}$-treated natural zeolite, according to the EDX analysis. In the EDX spectra of the natural zeolite, peaks appeared at 0.50, 1.50, and $1.80 \mathrm{keV}$ corresponding to the binding energies of $\mathrm{O}, \mathrm{Al}$, and $\mathrm{Si}$, respectively. These peaks approximately correspond to those reported for the TMA-A zeolites synthesized using hydrothermal methods. ${ }^{18}$ Further treatment of the $\mathrm{H}_{2} \mathrm{O}_{2}$-treated natural zeolite with a solution of gold ions, followed by reduction using $C$. inophyllum $\mathrm{L}$. leaf extract, produced more regularly shape particles, as shown in Fig. 3(c). Although element mapping using EDX

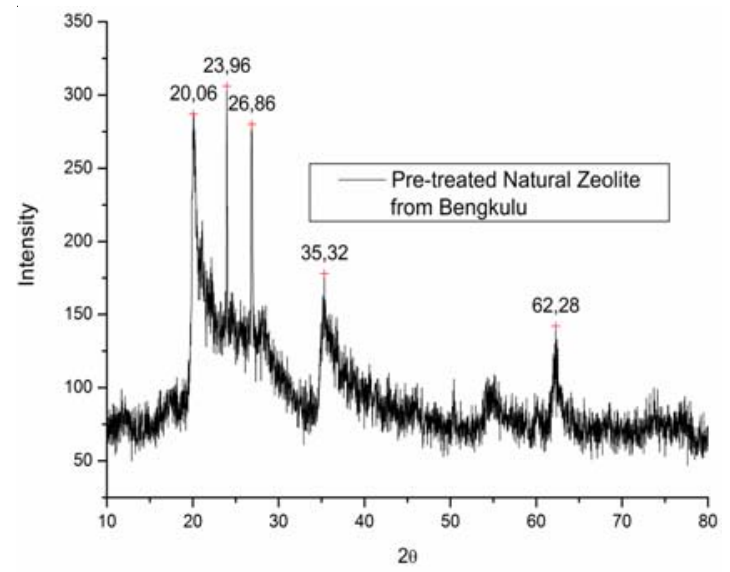

(a)
(Fig. 3(d)) did not definitively prove the presence of gold in the zeolite, the XRD results did suggest that metallic gold was present.

As reported in similar previous reports on zeolite-supported gold nanoparticles, the current metallic gold-coated natural zeolite has potential for use in various applications such as photocatalytic studies on RhB, reactive Red-198, and chlorophenols, ${ }^{19-120}$ the selective photooxidation of aromatic alcohols by irradiation with visible light, ${ }^{17}$ and the amperometric biosensing of spermidine. ${ }^{18}$

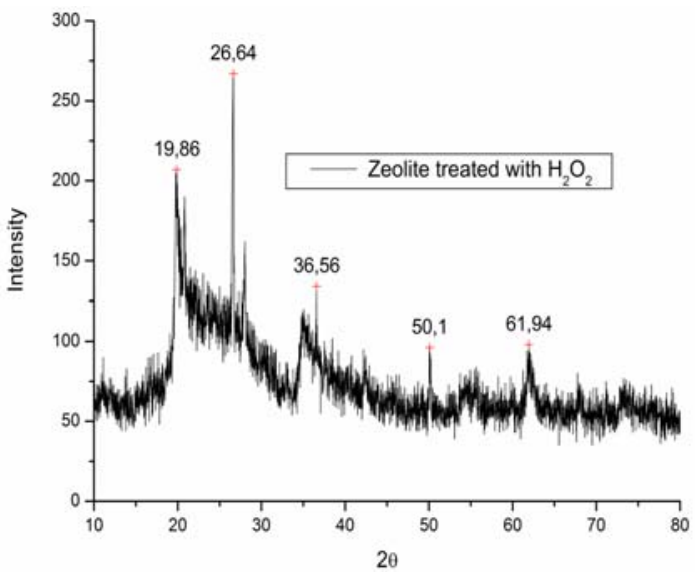

(b)

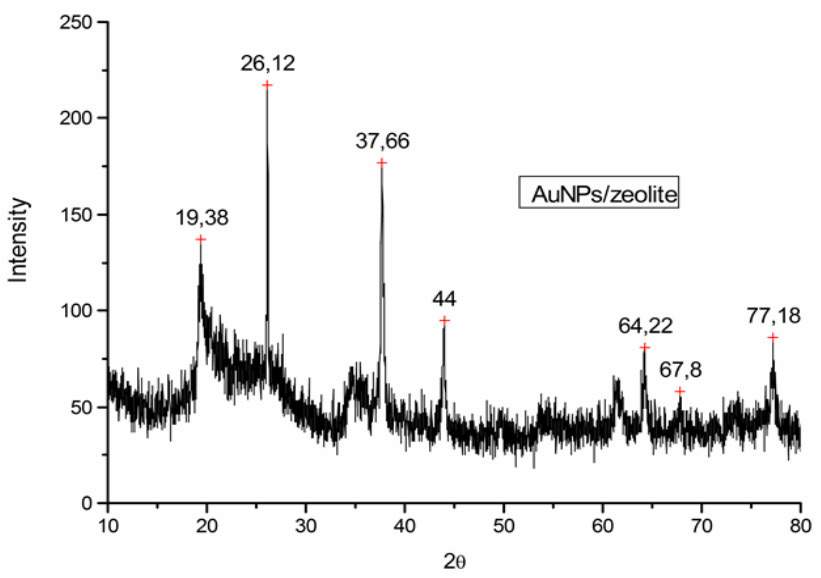

(c)

Fig. 2. XRD pattern of the (a) pre-tretated natural zeolite (b) $\mathrm{H}_{2} \mathrm{O}_{2}$-tretated natural zeolite (c) Gold metallic-coated natural zeolite 


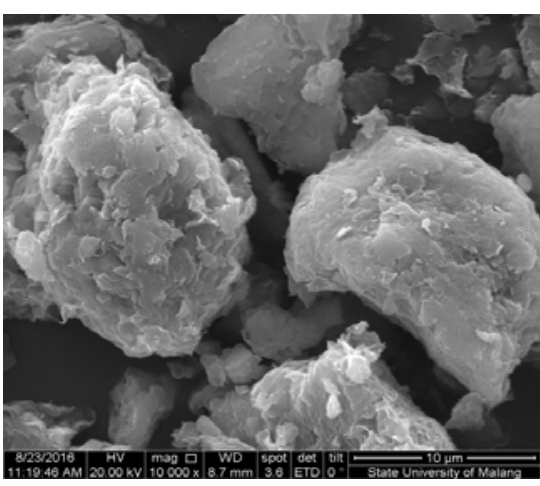

(a)

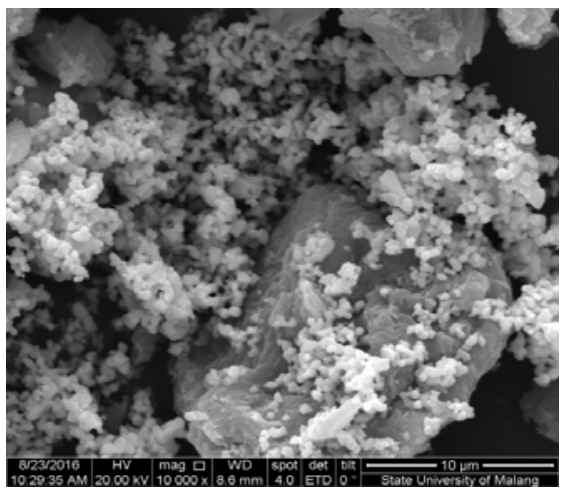

(c)

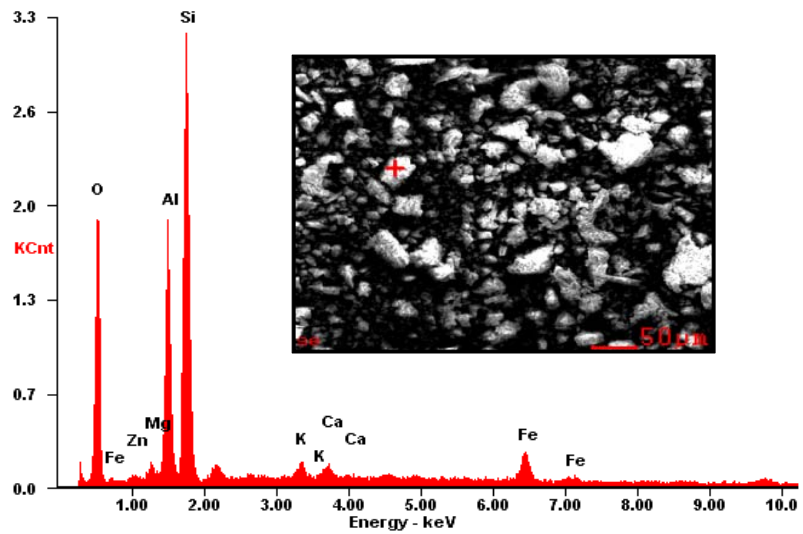

(b)

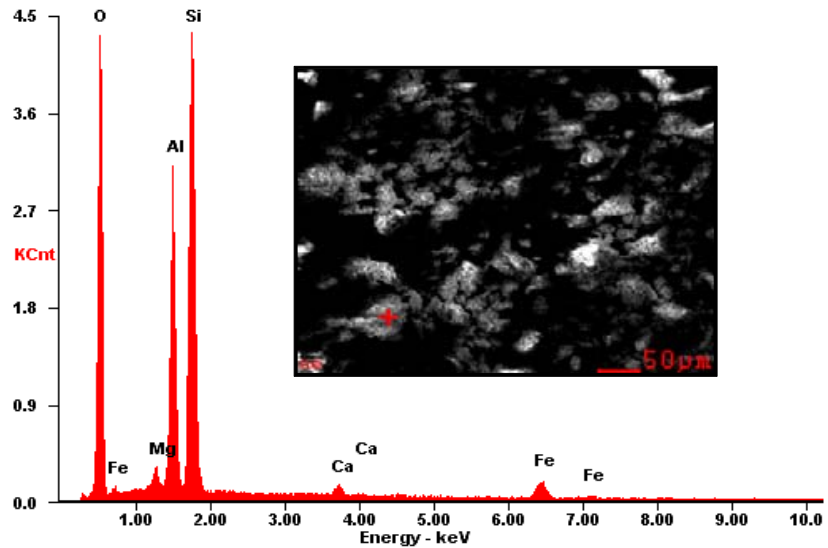

(d)

Fig. 3. (a) SEM and (b) EDX paterrn of $\mathrm{H}_{2} \mathrm{O}_{2}$-treated natural zeolite; (c) SEM and (d) EDX pattern of goldmetallic-coated natural zeolite

\section{CONCLUSION}

We successfully coated a natural zeolite with metallic gold using a green method that utilizes a leaf extract as the reducing agent. We obtained products that have potential as materials for various applications such as catalysts, antibacterial agents, agents for the photocatalytic degradation of organic pollutants, etc. Research in this field continues in our laboratory.

\section{ACKNOWLEDGEMENT}

S.Y.S and M.A thank Direktorat Riset dan Pengabdian Masyarakat, Kementerian Riset, Teknologi, dan Pendidikan Tinggi, the Republic of Indonesia for research funding. A.F. thanks the head of the Department of Chemistry at the University of Bengkulu for the opportunity as a Research Assistant at the Division of Inorganic Chemistry.

\section{REFERENCES}

1. Gunupuru, R.; Maity, D.; Bhadu, G.R.; Chakraborty, A.; Srivastava, D.N.; Paul, P. J. Chem. Sci. 2014, 126 (3) 627 - 635.
2. Yang, M.; Fujino, T. Chem. Phys. Lett. 2014, 592, $160-163$.

3. Lima, E.; Guerra, R.; Lara, V.; Guzmán, A. 
Chemistry Central J. 2013, 7 (11) 7 pages, DOI: $10.1186 / 1752-153 X-7-11$.

4. Ren, L.; Dong, J.; Cheng, X.; Xu, J.; Hu, P. Microchimica Acta, 2013, 180 (13) 1333 -1340.

5. Mielby, J.; Abildstrøm, J.O.; Wang, F.; Kasama, T.; Weidenthaler, C.; Kegnæs, S. Angewadnte Chemie Intl. Ed., 2014, 53 (46) 12513-12516.

6. Cao, S.-W.; Fang, J.; Shahjamali, M.M.; Wang, Z.; Yin, Z.; Yang, Y.; Boey, F.Y.C.; Barber, J.; Loo, S.C.J.; Xue, C. Cryst. Eng Comm. 2012, 14, 7229-7235.

7. Sakthivel, S.; Shankar, M.V.; Palanichamy, M.; Arabindoo, B.; Bahnemann, D.W.; Murugesan, V. Water Research, 2004, 38 (13) 3001- 3008.

8. Saikia, P.; Miah, A.T.; Das, P.P. J. Chem. Sci. 2017, 129 (1), 81 - 93.

9. Zhang, D. Polish J. Chem. Tech.2012, 14 (2) $42-48$.

10. Zhou, M., Zhang, J.; Cheng, B.; Yu, H. Intl. J. Photoenergy, 2012, Article ID 532843, 10 pages, http://dx.doi.org/10.1155/2012/ 532843.

11. Sun, S.; Chen, C.; Sun, J.; Peng, Q.; Lü, K.; Deng, K. Procedia Env. Sci. 2013, 18, 620 - 624.

12. Alshammari, A.; Bagabas, A.; Assulami, M.; Arabian J. Chemistry, Available online
November 10, 2014. http://dx.doi.org/ 10.1016/j.arabjc.2014.11.013.

13. Tan, Y.N.; Wong, C.L.; Mohamed, A.R. ISRN Materials Science, 2011, Article ID 261219, 18 pages, doi:10.5402/2011/261219.

14. Kaur, S.; Bhalla, V.; Kumar, M.; ACS Applied Materials \& Interfaces, 2015, 7 (30), 16617 - 16624.

15. Yudha S., S.; Mardlia, Z.A.; Angasa, E.; Suharto, T. E.; Nishina, Y. In Proceeding The 9th Joint Conference on Chemistry, 2014, Semarang, Indonesia, November 12-13, 2014.

16. Zhironga, L.; Uddin, M.A.; Zhanxuea, S.; Spectrochimica Acta Part A, 2011, 79, 1013 - 1016.

17. Zhang, X.; Ke, X.; Zhu, H. Chem. Eur. J. 2012 , 18, 8048 - 8056.

18. Chauhan, N.; Jain, U.; Gandotra, R.; Hooda, V. Electrochimica Acta, 2017, 230, 106 -115.

19. Reddy, G.R.; Balasubramanian, S.; Chennakesavulu, K. RSC Adv., 2015, 5, 81013 - 81023.

20. León, E.R.; Rodríguez, E.L.; Beas, C.R.; Plascencia-Villa,G.; Palomares, R.A.I. J. Nanomaterials, 2016, Article ID 9541683, 10 pages, http://dx.doi.org/ 10.1155/2016/ 9541683. 